\title{
Scientific research misconduct in social science research:What is it and how can we address it?
}

\begin{abstract}
Scientific misconduct is on the rise with the increasing emphasis on research by many academic institutions. A review of the literature shows various reasons behind this trend, from the difficulty of publication to the constant pressure to publish in academia. Further, lack of systematic reporting standards is one of the major contributing factors towards misconduct and unethical practices in scientific research. In this analysis, the authors will provide a detailed narrative on scientific misconduct, along with possible strategies to address this common unethical practice among social science researchers. This article will define and discuss the practices of falsification, fabrication, and plagiarism along with suggestions about how to avoid them.
\end{abstract}

Keywords: research, ethics, fabrication, falsification, plagiarism, misconduct

\author{
Volume 2 Issue 2 - 2018
}

\author{
Henry Poduthase,' Lisa Garza, ${ }^{2}$ Jennifer \\ Wood' \\ 'Department of Education and Social Science, University of \\ West Texas A\&M, USA \\ ${ }^{2}$ Department of Political Science and Criminal Justice, University \\ of West Texas A\&M, USA
}

Correspondence: Henry Poduthase, Department of Education and Social Science, Assistant Professor of Social Work, University of West Texas A\&M, USA, Tel 806-65I-2628, Email hpoduthase@wtamu.edu

Received: December 23,2017 | Published: March 14,2018

\section{Introduction}

Research is the driving force for innovations and technical advancement in the world. These innovations and advancements have propelled various dynamic, substantial, and comprehensible social changes. However, there are instances where these scientific contributions are clouded by scientific misconduct. This happens due to the fact that "Research is an act of imagination and innovation; yet it requires coordination and control of people, technologies, and research materials. ${ }^{1}$ The daunting task of coordinating and controlling human beings and their actions is often unrealistic, bringing us to the improprieties that occur in the research process. In the policy proposed by U.S. Office of Science and Technology Policy, ${ }^{2}$ scientific misconduct is defined as fabrication, falsification, and plagiarism (FFP), specifically in proposing, performing, or reviewing research, or in reporting research results. There have been several attempts to accurately study the prevalence of research misconduct in the social sciences. Martinson et $\mathrm{al}^{3}{ }^{3}$ attempted to identify the rate of research misconduct by surveying several thousand researchers who were self-identified as being in their early or mid-term careers. The study identified ten behaviors of great concern by interviewing six focus groups of researchers from top-tier research universities. The ten behaviors identified included falsifying research data, plagiarism, and fabrication, to name a few. ${ }^{3}$ The results from the respective research were astonishing, with $33 \%$ of researchers surveyed admitting to misconduct in their research. Specifically, the proportion of mid-career respondents who admitted misconduct in their research was $38 \%$, compared to $28 \%$ of those in their early career. ${ }^{3}$ In this article, the authors will discuss the practices of fabrication, falsification, and plagiarism, along with suggestions to address and prevent them.

\section{Falsification, fabrication, and plagiarism}

Misrepresenting research results by falsification always has and continues to occur; however, it has only come to the forefront during the past couple of decades. The U.S. Office of Science and Technology Policy (OSTP) defined research misconduct as "fabrication, falsification, or plagiarism in proposing, performing or reviewing research or in reporting research results". ${ }^{3}$ Specifically, $\mathrm{OSTP}^{2}$ defines falsification as "manipulating research materials, equipment, or processes or changing or omitting data or results such that the research is not accurately represented in the research record." While falsification involves the alteration or omission of data to manipulate outcomes and findings, fabrication is the outright creation of nonexistent data, or the "invention of data or cases". ${ }^{4}$ It is considered the blatantly fraudulent presentation of otherwise nonexistent data. Price ${ }^{5}$ recounts the case of Harvard psychologist Karen Ruggerio who, in 2001 , retracted a previously published article due to questionable validity of her data. In fact, she eventually admitted to fabricating the data in five experiments and falsifying the research in yet another published article. Fanelli's ${ }^{4}$ study on reported ethical violations (via a meta-analysis of literature on the subject) in social research revealed that nearly two percent of researchers admitted to fabrication or some form of falsification, while $34 \%$ admitted to some form of "research misconduct." If greater than one-third of respondents admitted to this behavior, it stands to reason that the number may be far higher. ${ }^{4}$ On the other hand, "Plagiarism is the appropriation of another person's ideas, processes, results, or words without giving appropriate credit". ${ }^{2}$ From a legal standpoint, the United States copyright laws protect the expression of original ideas. The use of someone else's ideas or words without giving proper credit or attribution to the original author occurs frequently from student papers to scientific papers. Further, ${ }^{6}$ provides a more extensive definition that includes such practices as: turning in someone's work as your own; copying words or ideas from someone else without giving credit; failing to put a quotation in quotation marks; giving incorrect information about the source of a quotation; changing words but copying the sentence structure of a source without giving credit; and copying so many words or ideas from a source that it makes up the majority of your work, whether you give credit or not." Additionally, there is wide discussion about self-plagiarism. While many argue "how can someone self-plagiarize?, The American Psychological Association ${ }^{7}$ suggests that, "When duplication of one's own words is more extensive, citation of the duplicated words should be the norm' (p. 16) and further states that this usage must conform to legal notions of fair use.

\section{Discussion and suggestions}

The reasons for research misconduct are myriad and complex. Perhaps one of the issues that leads to this type of behavior is the pressure that researchers, and in particular tenure-track university faculties, experience to get published in order to attain tenure. Additionally, there is increasing pressure to obtain funding for research during a time when such funding is being cut from the academy and downsizing of faculty is the norm. Another 
rationale for misconduct its the need to fulfill the complex requirements and expectations associated with grants. ${ }^{3}$ In particular, researchers who are in mid-career expressed discontent and dissatisfaction in their careers. This is an important point to consider when the data from Martinson et al. ${ }^{3}$ discovered that researchers in their mid-career were more likely than those in their early or late careers to falsify, fabricate, and plagiarize their findings. According to an article that was published in the Chronicle of Higher Education ${ }^{8}$ a survey of 13,510 professors from 69 universities reported that associate professors are "some of the unhappiest people in academia. ${ }^{8}$ Robert Rhoads, a professor of the Globalization and Higher Education Research Center at the University of California at Los Angeles wrote that "after tenure lots of faculty go through a crisis of meaning, where they think: 'There has to be something more than writing research grants, publishing and teaching.' An associate professor starts to think: 'Why am I doing what I'm doing?". ${ }^{7}$ Upon further consideration, faculty members, while they are at the most stressed, unfulfilled, and unhappy in their career, finds themselves in a position where their workloads increase. The number of committees and other service commitments increase, teaching, advising students, and of course still trying to publish to earn the rank of full professor. Might this lead to researchers, at least in the academy, participating in research misconduct?

Falsifying, fabrication, and plagiarism are the most troubling of the problems we have found in research, but there are other types of misconduct that have been revealed. Again, Martinson et al. ${ }^{3}$ discovered the following occurred more frequently than the respective mentioned behaviors: using inadequate or inappropriate research designs; dropping observations or data points from analyses based on a gut feeling; inadequate record keeping; publishing the same data or results in two or more publications; and, finally, inappropriately assigning authorship credit. ${ }^{3}$ Federally-funded universities have been required to create and implement curricula for responsible and ethical research conduct, at both the undergraduate and graduate levels. This is meant, in theory, to protect against deceptive and unethical research practices. This curriculum deals with concerns of authorship, recognition and avoidance of bias, and understanding of plagiarism, falsification, and fabrication, amongst other ethical considerations. 5

It was determined that a key factor in whether this curriculum was integrated into practice was the oversight, role modeling, and mentorship of colleagues. Therefore, strong university mentoring programs for new faculty are vital to the integrity of faculty research. Additionally, unlike many medical journals, social science journals do not have any systematic reporting standards. The creation and implementation of systematic reporting standards would ensure that researchers document and disclose their methods of data collection and analysis. ${ }^{9}$ Braxton ${ }^{10}$ suggested refusing membership in academic and professional organizations if the university research integrity committee found them guilty of misconduct. Braxton ${ }^{10}$ further asserts the need for scientific journals to refuse to publish if the research is obtained through misconduct, and to assume some accountability for the veracity of the articles they accept for publication. Further, the researchers and publishers should ensure adherence to the highest ethical standards while developing the research methodology, as well as when reporting and publishing the findings. ${ }^{11}$ Whatever the rationales or reasons for research misconduct, the fact remains that when researchers falsify and fabricate their results, the consequences can be significant, especially in a time where any type of empirical study or research is being challenged. This "war on science," if you will, gains momentum when researchers and faculty manipulate their research and this too often is then interpreted as being "fake."Fraudulent research sullies legitimate, and often critical, studies and diminishes the confidence in the reliability and veracity of outcomes. Now more than ever, we are living during a time where facts are often deemed as "false" or "fake" and researchers must become more diligent and ensure they are reporting what they have indeed found, instead of taking short cuts or committing acts of outright dishonesty to achieve a personal or professional goal.

\section{Acknowledgment}

None.

\section{Conflict of interest}

None.

\section{References}

1. Hackett JE, Parker JN. Research groups. In Leadership in Science and Technology: A Reference Handbook. In: Bainbridge WS, editors. SAGE Publications; 2012. p. 1-390.

2. United States Office of Science and Technology Policy. Federal policy of misconduct. USA:2005.

3. Martinson BC, Anderson MS, De Vries R. Scientists behaving badly. Nature. 2005;435(7043);737-738.

4. Fanelli D. How Many Scientists Fabricate and Falsify Research? A Systematic Review and Meta-Analysis of Survey Data. PLOS ONE. 2009;4(5):e5738

5. Price M. Sins against science. American Psychological Association. 2010;41(7):1-44

6. http://www.copyright.gov/help/faq/

7. American Psychological Association American. The Publication Manual of the American Psychological Association. 6th ed. American Psychological Association. Washington, D.C.; 2010. p.1-290.

8. Wilson R. Why are associate professors so unhappy? The chronicle of higher education. USA:2012.

9. Miguel E, Camerer C, Casey K, et al. Promoting transparency in social science research. Science. 2014;343(6166):30-31.

10. Braxton JM. Towards a guiding professional framework for professional self-regulation in the community of academic profession. In: Braxton JM, Columbus, editors, Perspectives on scholarly misconduct in the sciences. Ohio State University Press,USA;1999. p.139-161.

11. Bainbridge WS. Leadership in Science and Technology: A Reference Handbook. SAGE Publications. USA;2012. p. 984. 